\section{Climate experts urge G20 to make stimulus green}

Climate-change analysts have urged leaders of the world's largest economies to invest more of their stimulus packages in reducing greenhouse-gas emissions.

Ottmar Edenhofer, co-chair of the Intergovernmental Panel on Climate Change, and Nicholas Stern, chair of the Grantham Research Institute on Climate Change and the Environment at the London School of Economics and Political Science, are aiming their report, Towards a Global Green Recovery, at politicians attending the G20 summit in London on 2 April.

The report estimates that almost $\$ 400$ billion of the total $\$ 2,610$ billion in economic-stimulus packages unveiled so far by the G20 nations has been earmarked for green measures such as renewable-energy projects (see chart). China says it will devote almost $35 \%$ of its stimulus spending (about $\$ 200$ billion) on green projects in 2009 and 2010 , and South Korea plans to devote more than $80 \%$ of its $\$ 38$-billion stimulus on green measures in the next four years. For more $\mathbf{G 2 0}$ coverage see www.nature.com/news.

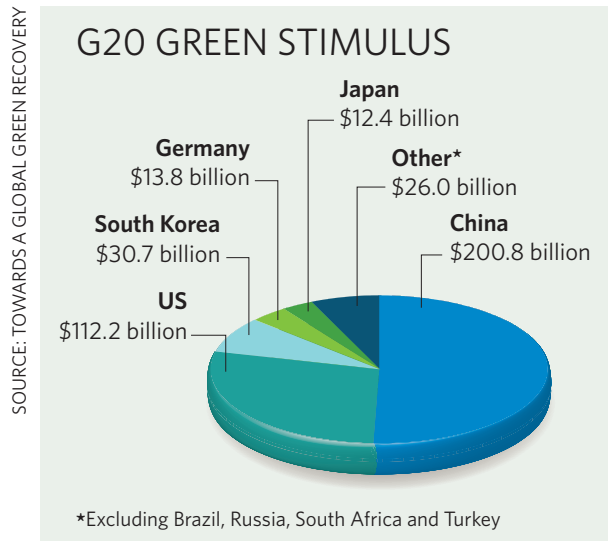

\section{Geometric work secures top maths prize}

Mikhail Gromov won the 6-millionNorwegian-kroner (US\$900,000) Abel Prize last week for his work on advanced forms of geometry. The Russian expatriate holds appointments at the Institute of Advanced Scientific Studies outside Paris and the Courant Institute of Mathematical Sciences at New York University. The Abel committee cited Gromov for his contributions to the study of Riemannian geometry, symplectic geometry and group theory.

Gromov is "renowned among mathematicians for his original approach", says Ian Stewart, a mathematician at the University of Warwick, UK, and his work has guided many other mathematicians and

\title{
Grazing limits effects of ocean fertilization
}

Preliminary results from a controversial Indo-German ocean fertilization experiment (LOHAFEX) have cast doubt on whether stimulating algal growth can help the sea sequester substantial amounts of carbon dioxide.

Earlier this year, researchers aboard the German research vessel Polarstern (pictured) poured 20 tonnes of iron sulphate over a 300-squarekilometre area of the Southern Ocean around the Antarctic (see Nature 457, 243; 2009).

However, grazing by small crustaceans prevented blooms from growing as much as some had hoped, according to Germany's Alfred Wegener Institute for Polar and Marine Research in Bremerhaven, one of the experiment's backers. Furthermore, a lack of silicic acid in the water restricted the growth of diatom plankton, which are more resistant to predation than the algae. The fertilization therefore removed only a "modest amount" of carbon from the environment.

physicists. The Abel Prize was founded in 2003 by the Norwegian Academy of Science and Letters to complement the Nobel prizes, which do not reward work in pure mathematics.

For a longer version of this story, see http://tinyurl.com/abelprize.

\section{Drug patent pools start to take shape}

GlaxoSmithKline, the world's secondlargest pharmaceutical company in terms of sales, has fleshed out proposals outlined last month to create a pool for companies to share patents to boost research into neglected diseases (see Nature 457, 1064-1065; 2009).

The company says that it will put some 500 patents and 300 pending applications into the pool, and has confirmed that on 1 April it will cut the price of its drugs in the world's 50 poorest countries to no more than $25 \%$ of prices in the developed world.

On 24 March, Ivan Lewis, the UK minister for international development, called for other pharmaceutical companies to contribute to both GlaxoSmithKline's patent pool and another pool for AIDS drugs that is being established by UNITAID, an international organization that negotiates lower drug prices.

\section{Gates supports Chinese tuberculosis drive}

China this week announced new measures to tackle its growing problem with tuberculosis (TB). On 1 April, health minister Chen Zhu and Bill Gates announced a partnership, supported by a 5-year US\$33-million grant from the Bill \& Melinda Gates Foundation, to pilot new diagnostic tests, monitoring strategies and treatments for the disease. The Chinese government will scale up the most effective of these trials.

A day earlier, the Chinese Academy of Sciences and the Gates-supported Global Alliance for TB Drug Development signed a partnership to search for anti-TB drugs among Chinese herbal medicines.

The announcements came at the start of a three-day meeting in Beijing, organized by the World Health Organization, where health officials from 27 countries are discussing how to control multidrug-resistant TB.

\section{Fossils protected in US land legislation}

After nearly 20 years, US scientists have won approval for a law that seeks to protect vertebrate fossils found on federal lands.

The US Vertebrate Paleontological Resources Preservation Act was included in omnibus land-management legislation signed into law on 30 March by President Barack Obama.

The bill means a permit is needed to collect any scientifically significant vertebrate fossil, officials say. But it would allow 'casual collecting' of common fossils. Details of how the law will be applied are yet to be finalized.

Officials at the Society of Vertebrate Paleontology have pushed for the legislation because of the widespread practice of commercial collecting, where important specimens may be sold and not recorded in the scientific literature.

\section{Correction}

The article 'Supplanting the old media?' (Nature 458, 274-277; 2009) incorrectly stated the web traffic received by Derek Lowe's blog, In the Pipeline. The blog receives around 200,000 page views each month, not each week. 